\title{
Technology Research of Sewage Pipe Network on Initial Rain Water Receiving Capacity
}

\author{
Fengchao Liang ${ }^{1}$, Mou Lv ${ }^{1, a}$, Xiaobo Miao ${ }^{1}$ and Jie Song ${ }^{1}$ \\ ${ }^{1}$ School of Environment and Municipal Engineering, Qingdao University of Technology, 266033 Qingdao, China
}

\begin{abstract}
Taking a certain area of a coastal city as the research object, based on the measured data, the model of rainwater pipe network and the hydraulic model of sewage pipe network in the study area were established based on SWMM. According to the set interception target combined with the established SWMM rainwater network model, the specific volume of Rain Water in the initial stage of each Rain Water discharge port is calculated, which is given to the sewage trunk pipe in the form of time series to realize the initial Rain Water interception control and analyze the receiving capacity of the sewage pipe network. In this study, $20 \%$ of the initial Rain Water was set up in the study area, which was given in the form of time series to the nodes in the sewage pipe network model. After the initial Rain Water was cut off $20 \%$, part of the pipe segment and the node appeared overload phenomenon, but there was no overflow. After $30 \%$ initial Rain Water interception, overflow occurred in some pipe segments.
\end{abstract}

\section{Introduction}

With the rapid development of the city, the urban drainage network and sewage treatment facilities are becoming more and more perfect. The point source pollution in the city has effectively controlled the pollution of the natural water body, and the non-point source pollution caused by rainfall has become the primary factor to pollute the natural water body [1]. The rainwater and sewage separation drainage system is a relatively reasonable scheme, but pollution of Initial Rain Water is also quite serious [2]. The outdoor drainage design code (GB50014-2006) stipulates that the new urban drainage system should be divided. Although the distributary drainage system can reduce the impact of rainfall on sewage treatment plants and drainage networks, at the beginning of the Rain Water, a large amount of polluting gases in the air were dissolved, then dropped to the ground and then washed over the roof, and roads. As a result, Rain Water carried a large number of pollutants such as heavy metal ions in the initial stage, and the urban water environment was seriously polluted by diverging drainage system into the natural water body. The pollutant content in the initial Rain Water runoff is the highest in the whole runoff process, which is called the initial erosion effect of rainfall $[3,4]$. Environmental Protection Agency (EPA) studies on water pollution show that non-point source pollution causes about $30 \%$ of surface water pollutants to exceed the standard. The results show that the concentration of Rain Water pollutants is very high in the separation system, especially in the initial stage of Rain Water, and the initial concentration of Rain Water pollutants is even higher than that of some domestic sewage. Therefore, it is necessary to study Rain Water in the early stage of interception.

\section{Model construction}

The model of rainwater pipe network can be established by SWMM, and the hydraulic model of sewage network can be established at the same time. Because there are many examples of rainwater pipe network model and few examples of sewage pipe network hydraulic model, the following emphasis is put on introducing the method of establishing sewage pipe network hydraulic model.

\subsection{The Establishment of Rainwater Pipe Network Model}

The model of rainwater pipe network is established for the study area. The model consists of 60 nodes and 60 canals, 51 catchment areas and 6 discharge outlets. The generalizations of Rain Water system are shown in Fig. 1 .

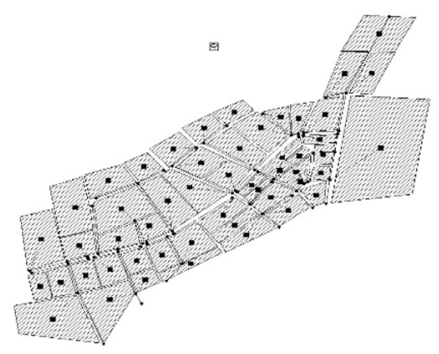

Figure 1. Schematic diagram of rainwater pipe network

\footnotetext{
a Corresponding author: Lvmou1@163.com
} 


\subsection{Establishment of hydraulic model for sewer network}

First, input the basic data in turn, then divide the catchment area according to the actual situation of pipe network confluence, topography, slope and so on, and divide the catchment area from the area of catchment area and the proportion of industrial land area of each catchment area. Household water consumption index and other data to calculate the flow. There are two methods for modeling the input flow of sewerage network system with SWMM. The first is to directly input the calculated inflow, and the second is to generalize the calculated amount of domestic sewage into the amount of water in the catchment area under a certain rainfall intensity. The amount of industrial waste water is generalized to the inflow flow of the corresponding node.

The basic data is imported into the model one by hand. This method has a lot of workload and is easy to make mistakes in the input process. Basic data can be processed through EXCEL batches and imported directly into the model inp file opened with notepad. Or on the basis of Gis data, the shp file can be converted directly into the model inp file, this method can greatly reduce the workload of modeling.

The studied area is divided into 43 catchment areas according to topography, slope and other factors. The main purpose of modeling sewage network by SWMM is to calculate the inflow of each node and to provide the basis for the calculation of the inflow. By consulting the drainage plan of this city, the per capita comprehensive domestic water consumption index $305\left(\mathrm{~L} \cdot \mathrm{P}^{-1} \cdot \mathrm{d}^{-1}\right)$ is obtained. According to the population density and the service area of each node in this area, the domestic water consumption can be calculated [5]. The population density of this area is 1050 people / square kilometer, and the area of node service is the area of catchment area. Industrial water consumption can be obtained according to the proportion of industrial land area. The comprehensive decontamination coefficient of the municipal sewage is 0.85 , and the flow rate of each node can be obtained.

As shown in figure 2, there are 61 sewage inspection wells, 61 pipelines and 1 discharge outlet in the study area.

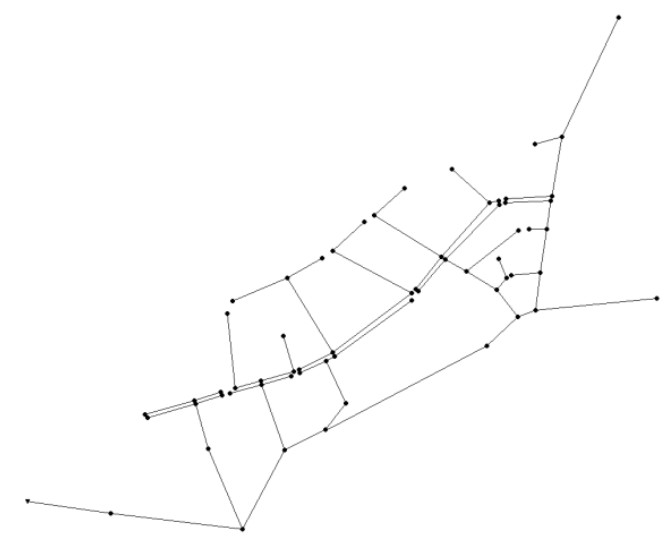

Figure 2. Schematic diagram of sewage pipeline network

\section{Interception control principle}

The study area drainage system is the complete distributary drainage system. In the distributary drainage system, only the initial Rain Water discharge from the Rain Water discharge outlet is required. The initial Rain Water interception is determined according to the set interception target, and the latter Rain Water lets it be discharged into the river. Because there are no pollutant parameters in the SWMM model to control the initial Rain Water interception, the initial Rain Water interception control can only be achieved by assigning the runoff time series to the main pipe node. The flow interception diagram is shown in figure 3 .

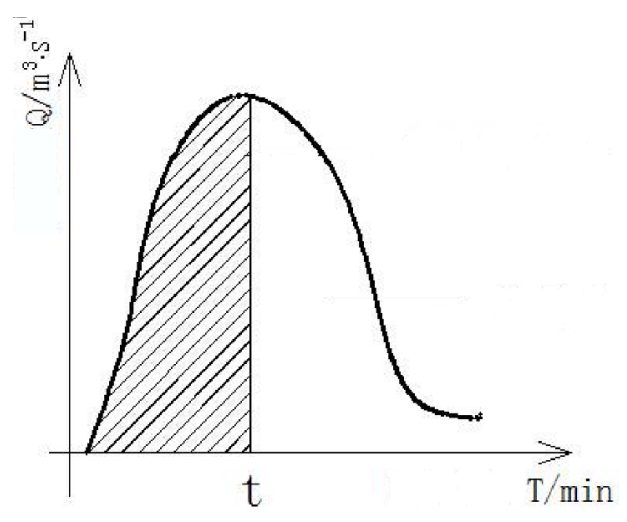

Fig. 3. Initial rainwater interception diagram

The Flowmeter adopts the velocity area method, the velocity measurement uses the Doppler ultrasonic measurement principle, the liquid level measurement uses the pressure or the ultrasonic wave measurement principle, simultaneously carries on the separate continuous measurement to the velocity, the liquid level. The measuring frequency is set at $1 \mathrm{~min}$, and the on-line flow rate of each catchment area is monitored 24 hours on line, and 1440 data can be obtained stably per day for each equipment.

From Fig. 3 we can calculate the discharge flow of the discharge outlet before a certain period of time by the rainfall runoff process line of the discharge outlet in the rainwater pipe network model. By calculating the percentage of shadow area to total area before $t$, this percentage is the target of interception. Through the discharge process line of each discharge port, the corresponding $t$ value of each discharge outlet can be found under the interception target, and then the runoff time series before the time $t$ of each discharge outlet is assigned to the main sewage pipe node in the sewage pipe network model. The initial Rain Water can be cut off in SWMM, then the water capacity of sewage network can be simulated, and its hydraulic operation condition can be analyzed.

If the initial Rain Water is to be cut off in a high recurrence period, it is necessary to build a special sewage interception trunk in the actual project, but there is only a sewage pipe network in the study area, and no sewage interception trunk pipe has been built, and the remaining space in the sewage pipe network is considered comprehensively, and so on many factors, such as the residual space in the sewage pipe network, are taken into account. This study will focus on the 
initial Rain Water interception at the recurrence stage $\mathrm{P}$ $=1$. Because the area is large and each outlet is responsible for the discharge, the cut-off target is tentatively set at $20 \%$ and $30 \%$.

\section{Determination of time Series of Water discharge}

Taking the initial Rain Water of $20 \%$ interception as an example, this paper introduces in detail how to determine the time series of water discharge. The key of determining the discharge time series of each outlet is to find the corresponding $\mathrm{t}$ value. In the study area, there are 6 Rain Water discharge outlets. According to the $20 \%$ cut-off target set before, the flow process line of each Rain Water discharge port should be made and the mathematical statistics should be carried out, and $20 \%$ of the discharge flow before each outlet should be cut off into the nearby sewage trunk pipe.

The model of rainwater pipe network was simulated for 180 minutes. The discharge rate of 6 discharge outlets after simulation is statistically analyzed. Taking the discharge port P5 as an example, how to find $t$ value and determine the time series of water discharge flow are explained. The flow process of each discharge port is shown in Fig. 4.

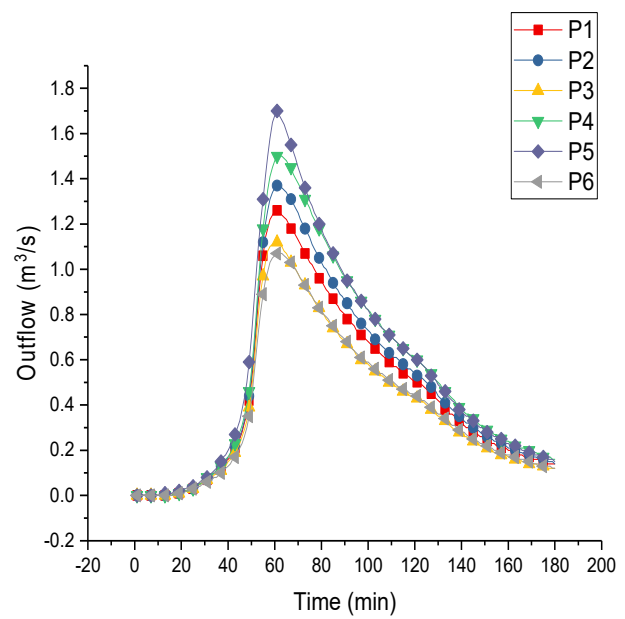

Fig. 4. Flow process line

The simulation results show that the total discharge rate of the P5 discharge port is $6865 \mathrm{~m} 3.20 \%$ of the flow rate is $1373 \mathrm{~m} 3$. And at the 64th minute, the sum of the previous discharge flow is $1373 \mathrm{~m} 3$. So the flow data of 64 minutes before the discharge port reaches $20 \%$ of the target of interception can be used as the input time series of the flow into the main sewage pipe node to achieve the initial Rain Water interception.

The time points for the discharge of the 6 outlets and the first $20 \%$ flow are shown in Table 1. After calculating the corresponding $\mathrm{t}$ value of 6 discharge ports, the outflow time series before $t$ of 6 discharge ports can be determined, that is, our interception target.

Table 1. Flow rate and $t$ value calculation table

\begin{tabular}{|c|c|c|c|}
\hline outlet & $\begin{array}{c}\text { Total } \\
\text { outflow }\end{array}$ & $\begin{array}{c}\text { Initial } \\
20 \%\end{array}$ & $\begin{array}{c}\text { The Initial 20\% } \\
\text { of the flow }\end{array}$ \\
\hline
\end{tabular}

\begin{tabular}{|c|c|c|c|}
\hline name & $\mathbf{( m 3 )}$ & $\begin{array}{c}\text { outflow } \\
(\mathbf{m} 3)\end{array}$ & $\begin{array}{c}\text { corresponds to } \\
\text { the t }(\mathbf{m i n})\end{array}$ \\
\hline P1 & 5214 & 1042.8 & 64 \\
\hline P2 & 5746 & 1149.2 & 62 \\
\hline P3 & 4765 & 953 & 64 \\
\hline P4 & 6123 & 1224.6 & 61 \\
\hline P5 & 6865 & 1373 & 61 \\
\hline P6 & 4118 & 823.6 & 60 \\
\hline
\end{tabular}

\section{Analysis on acceptance capacity of sewage Pipe Network}

The time series before the initial Rain Water response time of $20 \%$ of the discharge interception were determined, and the six time series were assigned to the nearby main sewage pipe nodes respectively. The initial Rain Water inflow time is $8: 00$, the initial time is $7: 30$, and the simulation time is 150 minutes. The initial Rain Water inflow node of the sewerage network is shown in Table2.

Table 2. Inflow node corresponding to each rainwater discharge port

\begin{tabular}{|c|c|c|c|}
\hline $\begin{array}{c}\text { outlet } \\
\text { name }\end{array}$ & $\begin{array}{c}\text { Initial rain } \\
\text { water inflow } \\
\text { node }\end{array}$ & $\begin{array}{l}\text { outlet } \\
\text { name }\end{array}$ & $\begin{array}{c}\text { Initial rain } \\
\text { water inflow } \\
\text { node }\end{array}$ \\
\hline P1 & W11 & P4 & W36 \\
\hline P2 & W16 & P5 & W38 \\
\hline P3 & W17 & P6 & W39 \\
\hline
\end{tabular}

\subsection{Acceptance capacity of sewage Pipe Network at $20 \%$ initial Rain Wate}

After the initial Rain Water of $20 \%$ interception, it can be seen from figure 5 that the over-loading phenomenon of WSG2N WSG33 in the sewage pipe segment reached the peak value of 1 at 8:54, maintained for 14 minutes at the peak value 1 , and then dropped sharply. The peak value of WSG33 reached 1 at 8:59 and lasted for 3 minutes. The fullness then plummeted to a normal range. From figure 6 , it can be seen that the sewage node W15N W16 appears overload phenomenon. The water depth of sewage node W15 reaches the peak value of $0.69 \mathrm{~m}$ at 8:59, then the peak value of $\mathrm{W} 16$ reaches $1.05 \mathrm{~m}$ at $9: 03$ and then decreases to the normal range at 9:03.

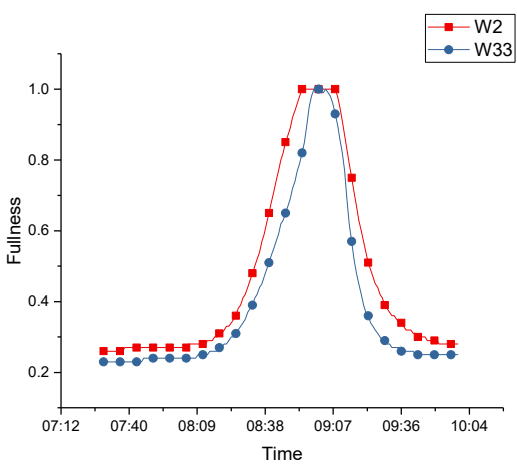

Figure 5. WSG2 and WSG33 fullness curve 


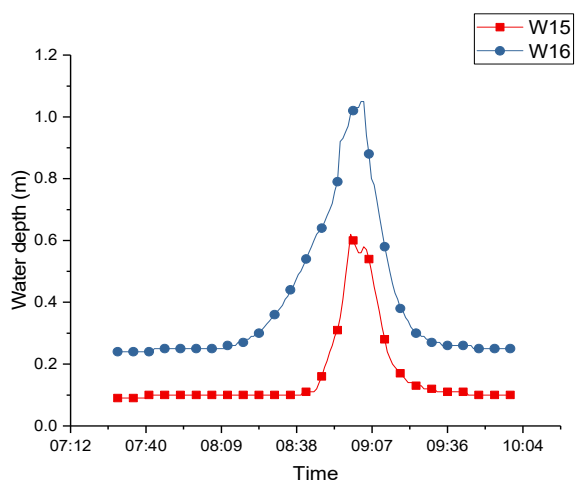

Figure 6. WSG2 and WSG33 water depth curve

After the initial Rain Water of $20 \%$ interception, although the phenomenon of overload appeared in the sewage pipe section WSG2WG33 and the sewage node $\mathrm{W} 15 \mathrm{~W} 16$, but due to the large residual space of the sewage network in this area, the operation condition of the sewage pipe network is better, so there is no overflow phenomenon. Although the interception of $20 \%$ of the initial Rain Water has a partial impact on the sewage network, it does not affect the normal operation of the sewage network, that is, the sewage network can hold $20 \%$ of the initial Rain Water.

\subsection{Acceptance capacity of sewerage pipe network at $30 \%$ initial Rain Wate}

The time $\mathrm{t}$ value corresponding to the initial Rain Water of $30 \%$ interception is determined first, and then the outflow time series is further determined. After the initial Rain Water of 30\% interception, there are two nodes overloaded in multiple pipe segments. The water depth variation of overflow node W11 and W16 is shown in Fig. 7.

Table 3. Flow rate and $t$ value calculation table

\begin{tabular}{|c|c|c|c|}
\hline $\begin{array}{l}\text { outlet } \\
\text { name }\end{array}$ & $\begin{array}{c}\text { Total } \\
\text { outflow } \\
\text { (m3) }\end{array}$ & $\begin{array}{c}\text { Initial 20\% } \\
\text { outflow } \\
\text { (m3) }\end{array}$ & $\begin{array}{l}\text { The Initial } 20 \% \\
\text { of the flow } \\
\text { corresponds to } \\
\text { the } t \text { (min) }\end{array}$ \\
\hline P1 & 5214 & 1564.2 & 71 \\
\hline $\mathrm{P} 2$ & 5746 & 1723.8 & 70 \\
\hline P3 & 4765 & 1429.5 & 72 \\
\hline $\mathrm{P} 4$ & 6123 & 1836.9 & 71 \\
\hline $\mathrm{P} 5$ & 6865 & 2059.5 & 70 \\
\hline P6 & 4118 & 1235.4 & 71 \\
\hline
\end{tabular}

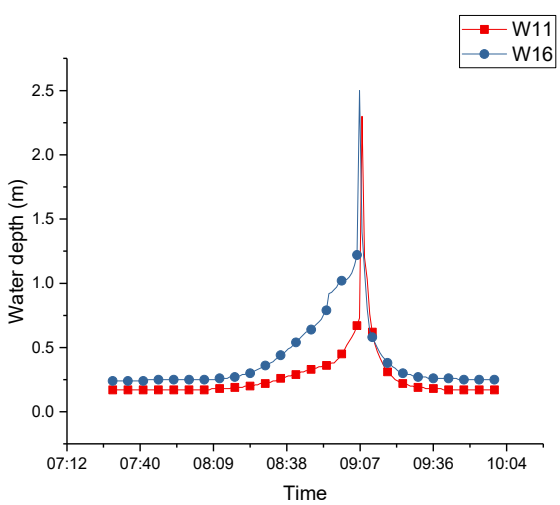

Figure 7. W11 and W16 water depth curve

Figure 7 shows that the water depth of the W11 node rises sharply at 9:07, reaching $2.3 \mathrm{~m}$, and then the water depth drops sharply to the normal range. The W16 node reaches $2.5 \mathrm{~m}$ at 9:06, and then the water depth drops sharply to the normal range. It can be seen that $30 \%$ of the initial Rain Water has exceeded the capacity of the sewage network in the study area, and the residual space of the sewerage network is not enough to accommodate $30 \%$ of the initial Rain Water.

\section{Conclusion}

In the rainfall recurrence period $\mathrm{P}=1,20 \%$ of the initial Rain Water in the intercepting study area entered the sewage pipe network, although some of the pipes and nodes will appear overload, but there is no overflow, indicating that $20 \%$ of the initial interception of the Rain Water did not exceed the capacity of the sewage pipe network; When $30 \%$ of the initial Rain Water is cut off into the sewerage network, some nodes of the sewerage network appear overflow phenomenon, so the initial Rain Water of the cut-off $30 \%$ has exceeded the capacity of the sewage network in the study area. In the early stage of interception, Rain Water enters the sewage pipe network, especially in the areas where air pollution, surface pollution or important natural water bodies exist. It is of great significance to reduce the pollution of urban water environment. By assigning the runoff time series to the node of the main sewage pipe to realize the control of the initial Rain Water, the limit of the acceptance capacity of the sewage network to the initial Rain Water can be found out, and the reasonable initial Rain Water interception can be determined.

\section{Acknowledgment}

National Natural Science Foundation of China (51478230)

\section{References}

1. Tsihrintzis V A, Hamid R. Modeling and Management of Urban Storm water Runoff Quality: A Review[J]. Water Resources Management, 9 (1997) 
2. Yin $\mathrm{X}$ B. Discussion on Pollution and Control Measures of Rainwater System in Rainwater and Sewage Separation Drainage System $[J]$. China Water \& Wastewater, 2014.

3. Geiger W F. Flushing effects in combined sewer systems. In: Proceedings of the 4th international conference on urban storm drainage. Lausanne, Switzerland, 1987.

4. Lee J H, Bang K W, Jr L H K, et al. First flush analysis of urban storm runoff.[J]. Science of the Total Environment,13 (2015) 